\title{
Flexural Properties and Sem Analysis Of Bamboo And Glass Fiber Reinforced Epoxy Hybrid Composites
}

\author{
${ }^{1}$ H. Raghavendra Rao, ${ }^{2}$ Y. Indraja, ${ }^{3}$ G. Meenambika Bai \\ ${ }^{1,2,3}$ Department pf Mechanical Enigineering G.P.R.Engineering College, Kurnool-518002, India
}

\begin{abstract}
The Flexural properties and Scanning electron Microscope analysis of Bamboo/glass fibers Reinforced epoxy Hybrid composites were studied. The effect of alkali treatment of the bamboo fibers on these properties was also studied. It was observed that flexural properties of the hybrid composite increase with glass fiber content. These properties found to be higher when alkali treated bamboo fibers were used in the hybrid composites. The elimination of amorphous hemi-cellulose with alkali treated leading to higher crystallinity of the bamboo fibers with alkali treatment may be responsible for these observations. The author investigated the interfacial bonding between Glass/Bamboo reinforced epoxy composites. The effect of alkali treatment on the bonding between Glass/Bamboo composites was also studied.
\end{abstract}

Keywords: Dendrocalamus strictus, bamboo fiber, Glass fiber, epoxy resin, SEM Flexural properties, hybrid composites.

\section{Introduction}

Several studies on the composites made from epoxy matrix and natural fibers like jute, wood, banana, sisal, cotton, coir and wheat straw were reported in the literature. Jindal (1) reported the development of bamboo fiber reinforced plastic composites using araldite (CIBA CY 230) resin as matrix. Though bamboo is extensively used as a valuable material from times immemorial (because of its high strength and low weight), the studies on this fiber reinforced plastics re meager. In the present work, the bamboo \& glass fiber reinforced high performance epoxy hybrid composites were developed and their Flexural properties with fiber content (with varying ratio of glass/bamboo fibers) were studied. The author investigated the interfacial bonding between glass/bamboo reinforced epoxy composites. The effect of alkali treatment on the bonding between glass/bamboo composites was also studied.

\section{Materials}

\section{Materials And Methods}

High performance epoxy resin LY 556 and the curing agent hardener HY 951 system were used as the matrix. Bamboo fibers (Dendrocalamus Strictus) were procured from Tripura state of India in the dried form. Some of these fibers were soaked in $1 \% \mathrm{NaOH}$ solution for $30 \mathrm{~min}$. to remove any greasy materials and hemicellulose, washed thoroughly in distilled water and dried under the sun for one week. The fibers with a thickness of $0.3 \mathrm{~mm}$ were selected in the mat form. The glass chopped strand mat was used in making the hybrid composite percentage.

\section{Preparation of mould}

For making the composites, a moulding box was prepared with glass with $200 \mathrm{~mm} \times 200 \mathrm{~mm} \times 3 \mathrm{~mm}$ mould (length $\mathrm{x}$ width $\mathrm{x}$ thickness)

\section{Preparation Of The Composite And The Test Specimens}

The mould cavity was coated with a thin layer of aqueous solution of poly vinyl alchol ( PVA) which acts as a good releasing agent. Futher a thin coating of hard wax was laid over it and finally another thin layer of PVA was coated. Each coat was allowed to dry for $20 \mathrm{~min}$ at room temperature. A $3 \mathrm{~mm}$ thick plate was made from the epoxy and hardener taken in the ratio of 100 and 10 parts by weight respectively. Then the moulding box was loaded with the matrix mixture and bamboo \& glass fiber in random orientation ( with varying percentage) and was placed in a vacuum oven which was maintained at $100^{\circ} \mathrm{c}$ for 3 hours to complete curing. After curing the plate was removed from the moulding box with simple tapering and it was cut in to samples for flexural test with dimensions of $150 \mathrm{~mm} \times 15 \mathrm{~mm} \times 3 \mathrm{~mm}$ are cut as per ASTM specifications. For comparision sake the specimen for matrix material were also prepared in similar lines. For Scanning electron microscope analysis the cryogenically cooled and fractured specimen surfaces were gold coated and the fractures surface was observed using scanning electron microscope. 


\section{Flexural Load Measurement}

The flexural and compressive modulii were determined using M/S Instron 3369 Model UTM. The cross head speed for flexural test were maintained at $10 \mathrm{~mm} / \mathrm{min}$ respectively. In each case 5 samples were tested and the average values are reported.

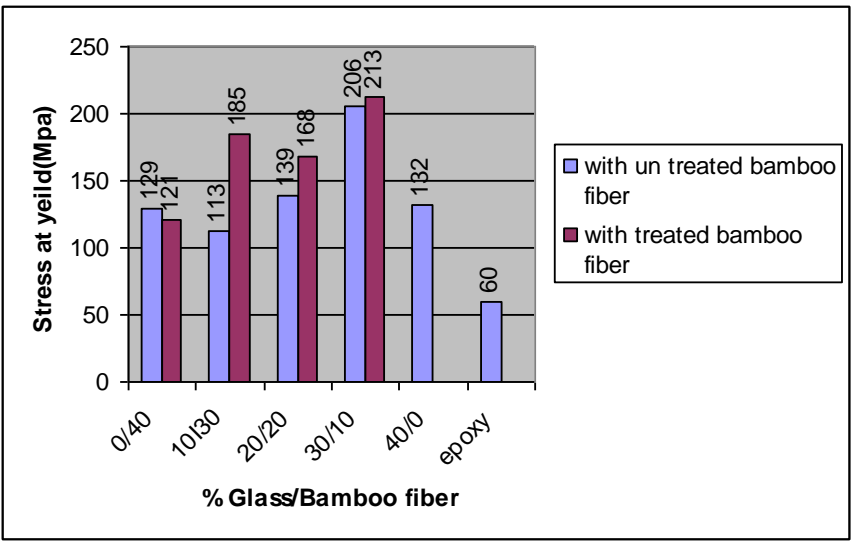

Fig-1 the variation of Stress at Yield with ratio of \% Glass/Bamboo fiber Reinforced Epoxy composites

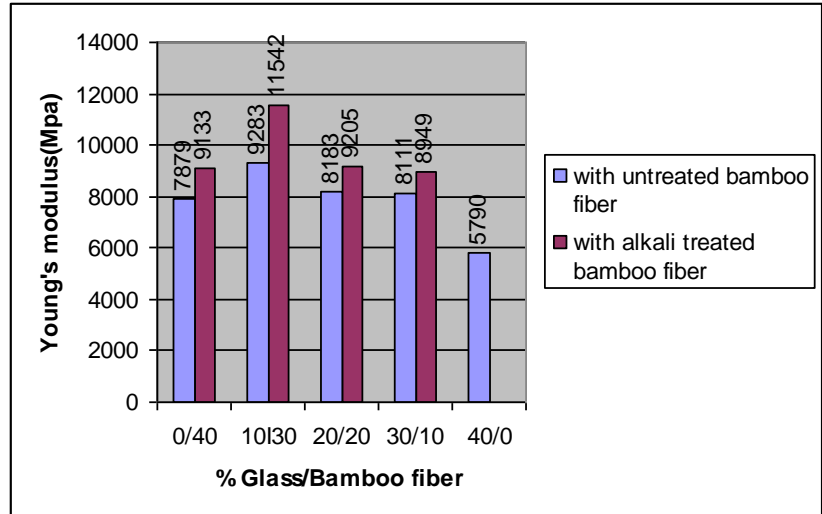

Fig-2 The variation of Flexural modulus with ratio of \% Glass/Bamboo fibers reinforced Epoxy composites

\section{EPOXY composites}

\section{Sem Analysis}

To probe the bonding between the reinforcement and matrix, the Scanning electron micrograms of fractured surfaces of glass/bamboo reinforced epoxy composites were recorded. These micrograms were recorded at different magnifications and regions. The analysis of the micrograms of the composites prepared under different conditions is presented in the following paragraphs.

\section{Untreated Bamboo Fiber}

The micrograms of fractured surfaces of untreated bamboo fiber are presented in figure 2 (a), (b), (c\&d ). Figure 2 (a)\&(b) represents the fractograms at two regions with a magnification of $100 X$. Figure 2 (c)\&(d) and the fractograms at these regions at magnification of 200X. From all these micrograms it is evident that fiber pullout is observed, indicating a poor bonding between the fibers. When the interfacial bonding is poor, the mechanical properties of the composites will be inferior. All the mechanical properties of the glass/bamboo fiber composites studied indicate that these properties are the least for these composites with untreated bamboo fibers. The poor adhesion is indicated in figure 2 supports this observation. 

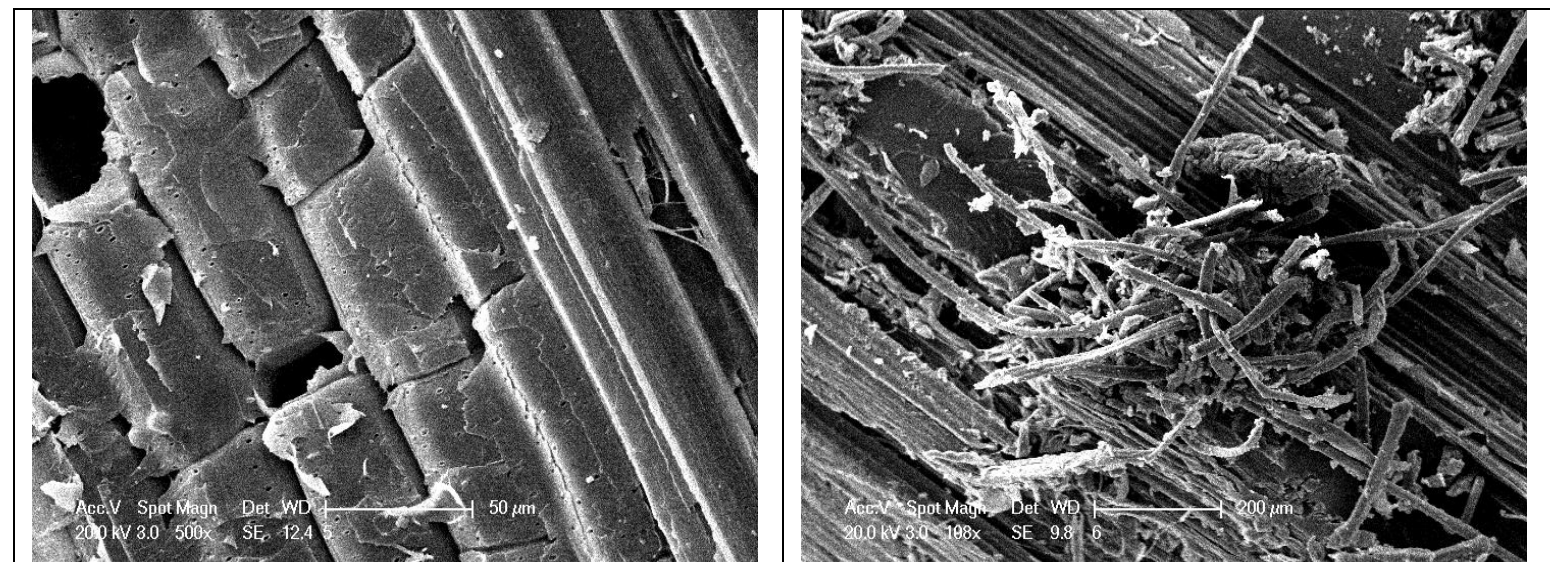

(a)

(b)

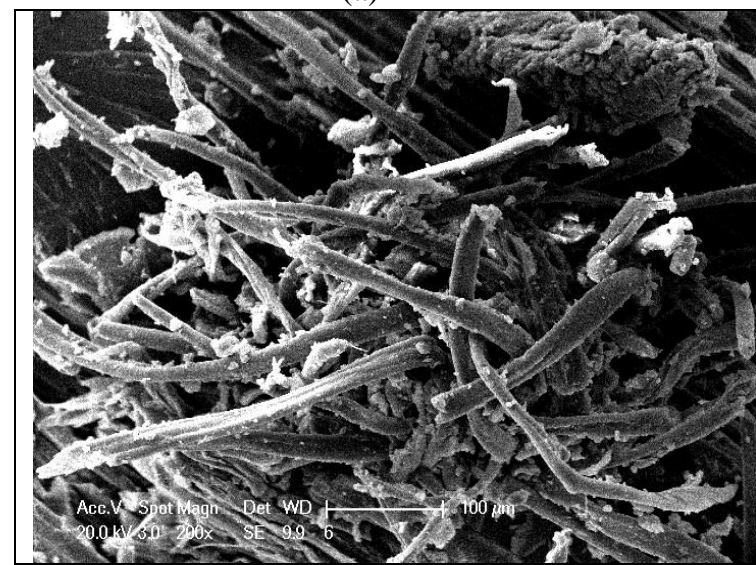

(c)

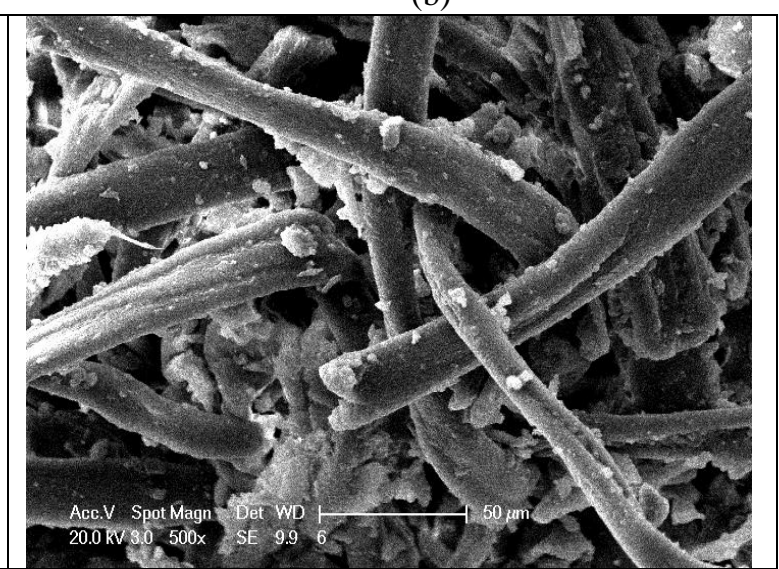

(d)

Fig 2:SEM of untreated Bamboo fiber (a) and (b) at two regions 100x magnification and (c) and (d) at two regions 200x magnification

\section{Treated Bamboo Fiber}

The fractograms of alkali treated bamboo fiber are presented in fig 3(a),(b),(c)\&(d).these fractograms were recorded at two different regions and 100X and 200X magnifications. From these micrograms it is clearly evident that the surface of the fiber becomes rough on alkali treatment. The elimination of hemi-cellulose from the surface of the bamboo fiber may be responsible for the roughening of the surface. Here, though the bonding is improved,fiber pullout is reduced. Thus the alkali treatment improved the bonding. This is in accordance with the mechanical properties of these composites.

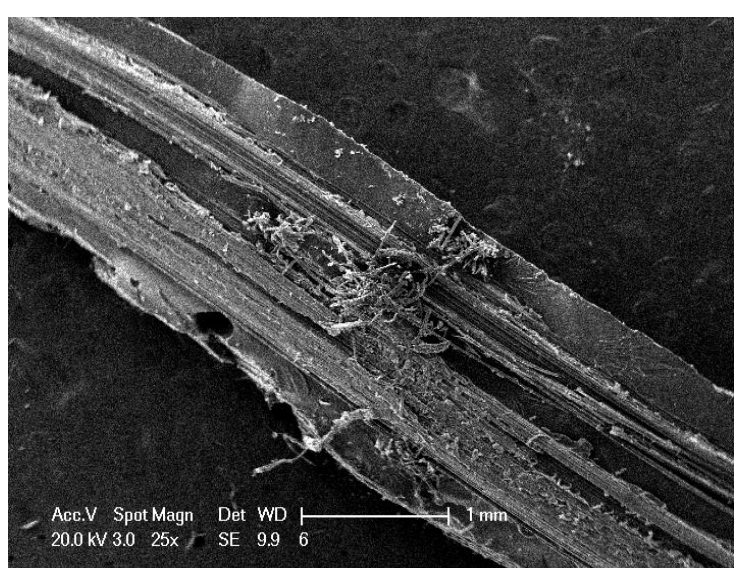

(a)

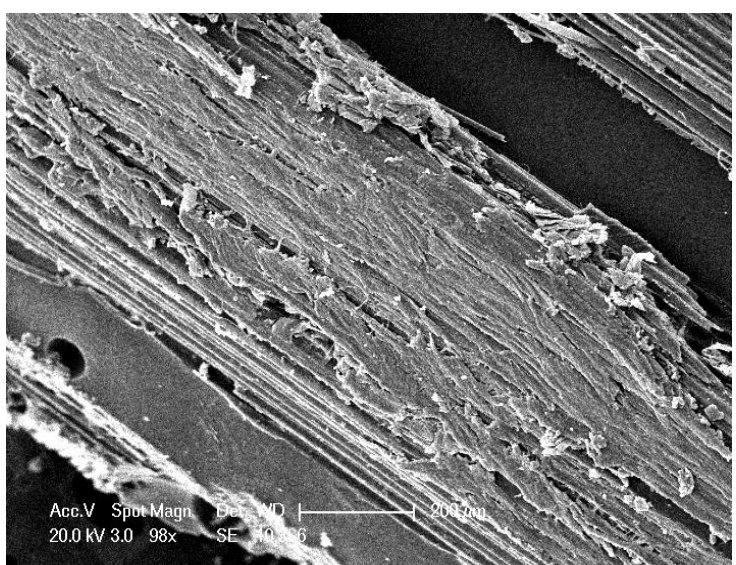

(b) 


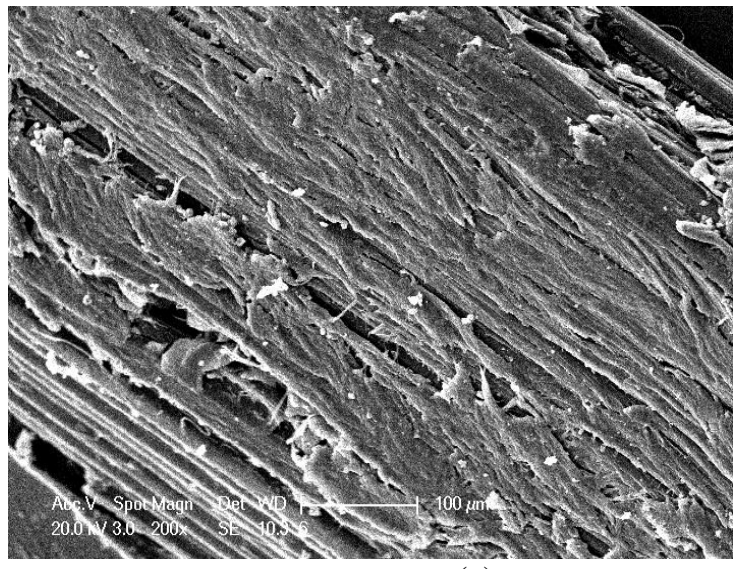

(c)

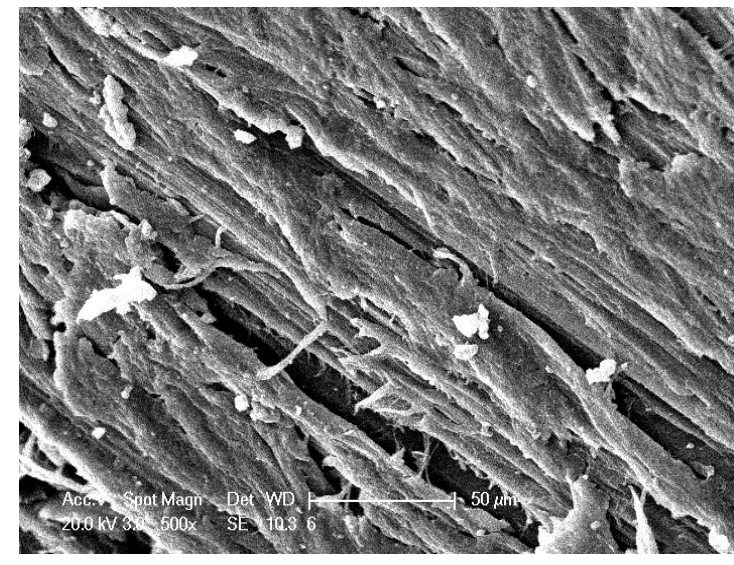

(d)

Fig 3 SEM of treated Bamboo fiber (a) and (b) at two regions 100x magnification and (c) and (d) at two regions 200x magnification

\section{Results And Discussion}

The variation of Flexural strength with the ratio of percentage glass/bamboo fiber in these composites is presented in fig-1, fig-2. In this case also the hybrid composites are found to have good Flexural properties. In the case of maximum strength, the values vary between 60 to $213 \mathrm{MPa}$. The Flexural strength of these composites are found to be enhanced when alkali treated bamboo fibers were used in the hybrid composites. Similarities observation was made by Varada Rajulu et al (2-9) and Srinivasulu et al(10) in the case of some bamboo composites and polymer coated bamboo fibers.

\section{Conclusion}

The hybrid composites of bamboo/glass fiber reinforced epoxy were made and their Flexural properties and SEM analysis studied. The effect of alkali treatment of the bamboo fibers on these properties was studied. These hybrid composites were found to exhibit good Flexural properties. The hybrid composites with alkali treated bamboo fibers were found to possess higher flexural properties. The elimination of amorphous weak hemi-cellulose components from the Bombay fibers on alkali treatment may be responsible for this behavior.

\section{References}

[1] Jindal, U.C (1986) development and testing of bamboo fibers reinforced plastic composites journal of composites 20: 19 (1986)

[2] Varada Rajulu , A., Narasimha Chary, K., Rama Chandra Reddy, G. Void content, density, weight reduction and mechanical properties of short bamboo fibers/ stryrenated polyster composites.j. Bamboo \& Ruttan.,2(2):95-102(2003).

[3] Varada Rajulu, A., Narasimha Chary, K., Rama Chandra Reddy, G.,Meng, Y.Z. Void content, density, weight reduction and mechanical properties of short bamboo fibers/ stryrenated polyster composites.j. reinforced plastics and composites, 23(2):127130.(2004).

[4] Varada Rajulu, A., Babu Rao, G ., Lakshminarayana Reddy, R. Chemical resistance and tensile properties of epoxy/poly carbonate blend coated bamboo fibers, journal of reinforced plastics and composites 20(4):335-340.(2001).

[5] Varada Rajulu, A., Ganga Devi, L., Babu Rao, G., Lakshminarayana Reddy, R. Chemical resistance and tensile properties of epoxy/unsaturated blend coated bamboo fibers, journal of reinforced plastics and composites 22(11) : 1029-1034. (2003).

[6] Varada Rajulu, A., Allah Baksh, S., Narasimha Chary Reddy, G.,Chemical resistance and tensile properties of short bamboo fiber reinforced epoxy composites, journal of reinforced plastics and composites 17(17): 1507-1511(1998).

[7] Varada Rajulu, A., Narasimha Chary, K., Rama Chandra Reddy, G., Babu Rao, G.,Ganga Devi, L Thermo gravimetric analysis of dendro calamus strictus bamboo fibers, journal of bamboo and Ruttan I(3): 247-250.(2002).

[8] Varada Rajulu, A., Narasimha Chary, K., Rama Chandra Reddy, G., Chemical resistance and tensile properties of stryrenated polyster - coated bamboo fibers, journal of fiber and textile research. 23: 49-51(1998).

[9] Varada Rajulu, A., Narasimha Chary, K., Rama Chandra Reddy, G. Chemical resistance and tensile properties of epoxy - coated bamboo fibers, Indian journal of fiber and textile research. 21: 223-224.(1998).

[10] Srinivasulu, S., Varada Rajulu, A ., Narasimha Chary, K., Rama Chandra Reddy, G. Chemical resistance and tensile properties of poly carbonate toughened epoxy - bamboo fibers, bulletin of pure and applied sciences. 25(2):137-142.(2006). 